\title{
Engendering Systemic and Cultural Leadership Practices in Residential College Communities: The Global Leadership Program at International House, the University of Sydney.
}

\author{
Bradley Kunda \\ Assistant Director \& Residential Life Officer \\ International House \\ University of Sydney
}

\begin{abstract}
This paper is an extract from a conference presentation delivered by the author at the $2^{\text {nd }}$ Collegiate Way International Conference in November 2016 in Canberra, Australia. While its aim was to build awareness around an aspect of the residential program at International House (namely its Global Leadership Program, which was researched, developed and coordinated by the author), the paper also discusses an emerging area of leadership discourse, and the ways it can be made relevant for university students.
\end{abstract}

Modern leadership thinking has come a long way since Gould and Kolb's assertion in 1964 that 'leadership behaviour can be observed only in relation to other persons who act in response to the leader and who are collectively referred to as the following' (Gould \& Kolb, 1964, p. 380). Today, leadership theories may be considered on a spectrum: on one hand, as the competencies and personality traits of an individual; and on the other, as complex interpersonal systems where leadership is observable at the level of organisational culture, rather than how specific individuals behave (Avery \& Bergsteiner, 2011). This summary, of course, simplifies a field that enjoys enormous scholarly interest; one from which an extensive range of sub-fields has now emerged (for example, sustainable leadership, ethical leadership, and neuro-leadership). Grappling with the wealth of literature to find something meaningful for tertiary students living in a residential college has been the challenge of convening the Global Leadership Program (GLP) at International House, the University of Sydney. Our objective has been to give all residents - not just those in formal leadership positions - opportunities to develop practical leadership skills while making meaningful contributions to their community.

In developing a mission for the GLP at International House, and in refining our scope of inquiry into leadership, we referred to our institution's core strengths and mission statement. Like our associated international partners, the community of International Houses Worldwide has always sought to intentionally cultivate international understanding and friendship (See http://www.ihouseworldwide.org). To this end, it was logical to pursue a vision for the GLP that was broadly encompassing of peoples' differences, while at the same time focussing very deliberately on global leadership competencies.

Osland, Bird, and Mendenhall et al. define global leadership as 'a process of influencing the thinking, attitudes and behaviours of a global community to work together synergistically toward a common vision and common goals' (2006, p. 204). This definition implies a refreshing view of leadership as culture, rather than a catalogue of the competencies and traits of an individual. This culturally-based approach to defining leadership is reflected in research by, among many others, Hughes, Ginnett and Curphy, who describe leadership as a process, not a position $(2015$, p. 4). Similarly, Avery and Bergsteiner explore leadership as a phenomenon that emerges when people interact in order to achieve shared goals in a particular context $(2011, \mathrm{p}$. 4). It is this rather more systemic view of leadership that is at the heart of the GLP, which attempts to promote global leadership potential among residents through the development of heightened self-awareness and cross-cultural competencies, as well as a commitment to the service of others. 
Fifty-five students have completed our program in 2015 and 2016. The program was open to all students residing at International House, not just those who held residential leadership positions. Students entered the program upon submitting a written statement about what they hoped to learn through the GLP, which was used to elicit some degree of insight into each applicant's own leadership development, as well as their personal and professional goals. Throughout the program, we asked these students to think about creating cultures where their peers could work collectively to achieve common goals. Structured in three stages, students would begin with self-awareness exercises and then attend skills workshops with expert guest speakers, before finally undertaking a project. This paper will discuss the three main aspects of the program and the methods for reviewing student impact for each of these in turn.

One of the exercises adopted to develop each student's self-awareness has emerged out of research conducted by Hunter in the United States. The Global Competence Aptitude Assessment (GCAA) is a two-stage assessment tool that measures an individual's 'internal readiness' and 'external readiness' with respect to their global competence (Global Competence Aptitude Assessment, 2017). Hunter defines global competence as 'having an open mind while actively seeking to understand cultural norms and expectations of others, and leveraging this gained knowledge to interact, communicate and work effectively outside one's environment' (Hunter, 2004, p. 81). Whereas intercultural competence relates to competencies specific for certain types of intercultural interaction (for example, between two specific cultures), global competence, while containing elements of intercultural competence, is more generalisable to interactions between any numbers of cultural groups (Hunter, 2006, p. 70). The intersection with leadership practices is in a person's aptitude to leverage their global competencies in order to interact and work effectively in culturally diverse environments, which relates nicely to the more systemic view of leadership taught in the International House GLP.

As part of the GCAA, students were given scores pertaining to their current levels of internal and external readiness for global competence. Dimensions of internal readiness included an individual's self-awareness, in addition to their levels of open-mindedness, attentiveness to diversity and risktaking aptitude. External readiness dimensions included global awareness, historical perspectives, intercultural capability and collaboration across cultures. As a cohort, the lowest scoring dimensions were, for internal readiness 'attentiveness to diversity', and for external readiness 'historical perspectives', which amounts primarily to a general knowledge of world history. Students were then required to select their weakest internal and external readiness dimensions and were given practical activities to assist in developing their aptitude in these areas. Upon completing these activities, students were asked to write a short reflective report on their learning experience.

The results of the reflective reports show genuine attempts to engage in self-learning and personal development. By way of a few examples, one Bangladeshi student acknowledged that he was not very open minded about other cultures, and took efforts to address this by actively learning about Australian history, and developing as a result a keen interest in Australian Aboriginal history. This student took out a book from the library on Aboriginal history and started watching relevant documentaries to develop his understanding. A Chinese student, focussing on developing this same internal readiness dimension, made friends with several Japanese students and visited Japanese restaurants with them, where she learned language customs for communicating with restaurant staff, and engaged in customary prayers before eating. Lastly, an American/Japanese student took the Harvard University online unconscious personal bias tests and wrote about discovering a natural automatic preference for 'White individuals' over 'Black individuals', which she noted may unfairly affect how she treats the people she works with.

While tools for the measurement and development of self-awareness are multifarious and 
numerous, the GCAA showed a uniquely relevant capacity to encourage students into conscientious self-reflection of their experience with knowledge of, and aptitude for, cross-cultural interaction. As more mature learners, students were given minimal supervision when undertaking their suggested development activities, which was considered appropriate given the highly personal nature of this aspect of their leadership development. The breadth of issues covered, and approaches attempted, in the GCAA reflective exercises suggests this tool is not only relevant but also helpful in encouraging a capacity for personal reflection and learning.

Stage 2 of the GLP consisted of four skills workshops, which were delivered by expert trainers. These highly practical workshops provided opportunities for students to discuss theories and skills associated with global leadership. These ranged from discussing Harald Bergsteiner's sustainable leadership theories, to developing strategies to effectively communicate and resolve conflict in cross-cultural contexts. Worthy of discussion here is the question of what the students actually gained from these workshops. How did these sessions frame their understanding of leadership?

A survey completed by all students at the conclusion of the program included the question: what is your current understanding of leadership? Virtually all responses dealt with the idea of leadership in a critical way. Respondents' approaches to defining leadership may be broadly classified as either others-centric (i.e. leadership as culture) or trait-based (i.e. leader-centric). Fifty-one per cent of participants gave qualitative responses that demonstrated an others-centric understanding of leadership, while only $18 \%$ answered with a more traditional trait-based response. Furthermore, $11 \%$ gave a trait-based response but acknowledged that the personal skills of an individual leader need to be adapted to the people being led. The remaining $20 \%$ of responses could not be said to fall within either category (Kunda, 2015). This outcome shows the majority of students reflecting a more sophisticated understanding of leadership as cultural practice rather than the more traditionally held view pertaining solely to the traits and competencies of an individual.

Stage 2 of the GLP was complemented by a series of public lectures delivered by various eminent leaders. Speakers were asked to reflect on their own experiences of leadership, and address the questions of what leadership means to them, what motivates their decision making, and what advice they would give to young aspiring leaders. Before the public talks, students enjoyed the opportunity to share a meal with each invited guest, which created opportunities for professional engagement and the development of networking skills.

In the final stage of the program, students were asked to design and implement a project that would bring residents of International House together in meaningful interaction. This project brief was kept intentionally broad so as to encourage the development of creative vision from each participant. Projects played a vital role in applying the content of the workshops and self-awareness exercises to transformational experiences that, paraphrasing the words of Mendenhall and his associates, enhance learning through high levels of complexity, intensity, emotional affect and relevance (Mendenhall, Osland \& Bird, 2013, p. 118).

Students were asked to write reflective pieces that drew on the concepts taught in the workshops when delivering on their projects. Projects ranged from organising charitable fundraising events, to convening academic talks, to running cultural celebration evenings. The wide range of events and initiatives implemented by the students added significant value to the residential life experience of all students residing in the House, thereby engendering student-focussed leadership within the residential life program itself.

Overall feedback from students in the completion survey was very strong, with $89 \%$ willing to unequivocally recommend the course to residents in the next year. At the macro level of evaluating 
the GLP's success at engendering leadership within the community, the wide range and student-led focus of projects supports a systemic view of leadership that ventures towards an 'organic' leadership paradigm (Avery \& Bersteiner, 2011, p. 11), where the residential life programming is in part generated by, and is flexible around the needs and interests of the students themselves, who create and propagate the vision of international understanding that is at the core of the International House mission.

\section{References}

Avery, G. \& Bergsteiner, H. (2011). Diagnosing leadership in global organisations (p. 7-16). Prahran, Victoria, Australia: Tilde Publishing and Distribution.

Global Leadership Excellence, LLC (2017). Global competence aptitude assessment - global competence model. Retrieved from http://www.globallycompetent.com/model/index.htm.

Gould, J. \& Kolb W.L. (1964). A dictionary of the social sciences. London, United Kingdom: Tavistock Publications.

Hughes, R., Ginnett, R. \& Curphy, G. (2015). Leadership: enhancing the lessons of experience (8th edn.). New York, NY: McGraw-Hill Education.

Hunter, W.D. (2004). Knowledge, skills, attitudes, and experiences necessary to become globally competent. (Unpublished $\mathrm{PhD}$ thesis). Lehigh University, United States of America.

Hunter, W.D. (2006). What does it mean to be globally competent? Journal of Studies in International Education, 2006 , $10(3), 267-285$.

International Houses Worldwide (2017). Official Website. Retrieved from http://ihouseworldwide.org.

Kunda, B. (2015). International House Global Leadership Development Program: Report on 2015 program (Unpublished report). The University of Sydney, Australia.

Mendenhall, M., Osland, J., Bird, A. et al. (2013). Global leadership: Research, practice and development (2nd ed). New York, NY: Routledge.

Osland, J., Bird, A., Mendenhall, M. et al. (2006). Developing global leadership capabilities and a global mindset: a review. In Günter Stahl and Ingmar Björkman (eds). Handbook of research in international human resource management. Cheltenham, UK: Edward Elgar Publishing.

The author may be contacted via

bradley.kunda@sydney.edu.au 